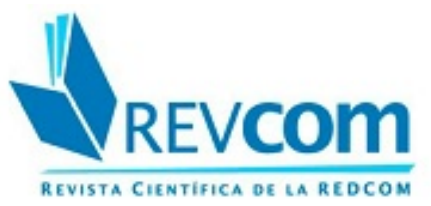

REVCOM. Revista científica de la red de carreras de Comunicación Social

ISSN: 2451-7836

redcom.revcom@gmail.com

Universidad Nacional de La Plata

Argentina

\title{
Aportes al debate sobre convergencia tecnológica en las prácticas de consumo audiovisual
}

Morales, Susana; Martínez Luque, Santiago

Aportes al debate sobre convergencia tecnológica en las prácticas de consumo audiovisual REVCOM. Revista científica de la red de carreras de Comunicación Social, núm. 10, 2020

Universidad Nacional de La Plata, Argentina

DOI: https://doi.org/10.24215/24517836e035 


\title{
Aportes al debate sobre convergencia tecnológica en las prácticas de consumo audiovisual
}

\author{
Contribuições para o debate sobre convergência tecnológica nas práticas de consumo audiovisual \\ New Inputs on the Debate about Technological Convergence in Audio Visual Consumption Practices
}

Susana Morales

DOI: https://doi.org/10.24215/24517836e035

Facultad de Ciencias Sociales. Universidad Nacional de

Córdoba, Argentina

susanamoralesar@yahoo.com.ar

Santiago Martinez Luque

Facultad de Ciencias Sociales. Universidad Nacional de

Córdoba, Argentina

santiagomartinezluque@gmail.com

\section{Resumen:}

Este artículo propone recuperar algunos datos producidos en el marco del proyecto Radios cooperativas y públicos. Estudios de consumo y audiencias radiofónicas en el Gran Córdoba (Primera y Segunda Parte) para debatir afirmaciones usuales que circulan en ámbitos académicos, de manera naturalizada, ligadas a las transformaciones recientes del consumo audiovisual. En particular, en este trabajo nos interesa aportar al debate sobre el proceso de convergencia mediática. Creemos que es necesario discutir ciertas imágenes de este proceso a partir de las cuales se afirma y reproduce que los nuevos medios y tecnologías de información y comunicación han venido a desplazar y reemplazar -estricta y definitivamente- a los medios audiovisuales tradicionales, tales como la radio y la TV. Así también aquellas aseveraciones en torno a las prácticas de consumo de determinados grupos etarios -especialmente de los jóvenes-. En ese sentido, si bien cabe reconocer el progresivo e incuestionable crecimiento de las nuevas tecnologías, internet y las redes sociales digitales como espacios de consumo audiovisual, entendemos que es necesario producir una mirada crítica sobre este proceso que nos permita tanto dar cuenta de las prácticas de consumo audiovisual como de las particularidades locales que podrían complejizar los datos generales con los que solemos contar.

Palabras Clave: estudio de audiencias, Investigación centrada en un problema, medición de audiencia, investigación sobre la comunicación.

\section{Resumo:}

Neste artigo, propomos recuperar alguns dados produzidos no âmbito do projeto Rádios cooperativas e públicas. Estudos de consumidores e audiências de rádio na Grande Córdoba (primeira e segunda parte) para discutir declarações usuais que circulam, de forma naturalizada, em campos acadêmicos ligados às transformações do consumo audiovisual. Em particular, neste trabalho, estamos interessados em contribuir para o debate sobre o processo de convergência da mídia. Acreditamos que é necessário discutir certas imagens desse processo pelas quais é afirmado e reproduzido que as novas mídias e tecnologias da informação e comunicação passaram a deslocar, de maneira estrita e definitiva, e substituir as mídias audiovisuais tradicionais, como rádio e TV, bem como declarações sobre as práticas de consumo de determinadas faixas etárias - especialmente de jovens. Nesse sentido, embora seja possível reconhecer o crescimento progressivo e inquestionável de novas tecnologias, internet e redes sociais digitais como espaços de consumo audiovisual, entendemos que é necessário produzir um olhar crítico sobre esse processo que nos permita dar conta das práticas do consumo audiovisual e das peculiaridades locais que podem complicar os dados gerais que geralmente possuímos.

Palavras-CHAVE: estudo de audiência, pesquisa focada em problemas, medição de audiência, pesquisa em comunicação.

\section{Abstract:}

This article proposes to recover some of the data produced in the framework of the Cooperative and public Radio projects. Consumption studies and radio audiences in the Big Córdoba Area (First and Second Part) to debate the usual affirmations that can be found in academic circles, which are made to appear natural, and linked to the recent transformations of audio visual 
consumption. We are interested in this particular case in contributing to the debate on the media convergence debate. We believe that it is necessary to discuss certain images of this process, and how people tend to affirm and reproduce that new media and information/communication technologies are here to replace and displace -once and for all-traditional audio visual media, such as radio and TV, because of these images. So too on those asseverations which revolve on certain aged group practices -especially young people. In this sense, although recognizing the unquestionable progress and growth of new technologies, internet and social digital media as areas of audio visual consumption, we understand that it is necessary to produce a critical view over this process, so as to take into account the audio visual consumption practices like the local particularities that could complexify the general data which we usually make do with.

KEYWORDS: audience studies, problem centred research, audience readings, communications research.

\section{INTRODUCCIÓN}

La investigación que da origen a este artículo se desarrolló en articulación con cuatro radios comunitarias del Gran Córdoba. Se trata de un proceso en el que se generaron distintos tipos de indagaciones en torno a las audiencias relevadas empíricamente y aquellas de tipo potencial de dichas emisoras, así como de los distintos vínculos que las mismas establecen con sus públicos. Durante los años 2016, 2017 e inicios de 2018 se trabajó con cuatro radios comunitarias de las ciudades de Alta Gracia, Cosquín, Unquillo y Carlos Paz ${ }^{1}$. Se realizaron ocho estudios, dos para cada una de las radios, uno de tipo cuantitativo y el otro cualitativo.

Estas emisoras son de creación reciente, ya que todas empiezan a transmitir entre los años 2008 y $2014^{2}$, en el marco de la discusión por la Ley de Servicios de Comunicación Audiovisual. En este contexto, nuestra investigación buscaba aportar a conocer las audiencias de estos proyectos, proporcionar pistas respecto a las posibilidades de crecimiento de las mismas y reconstruir algunas claves de lectura que permitieran comprender el modo en que las propuestas radiofónicas dialogaban y competían con lo propio de otros medios, en pos de potenciar las ofertas radiofónicas democráticas y de calidad (Magallanes, Ramos, et al, 2010; Kejval, 2017). En definitiva, un proyecto diseñado como aporte para pensar las audiencias audiovisuales y la sustentabilidad de los proyectos comunitarios, generando información rigurosa, actualizada y precisa que les permitiera repensar los escenarios audiovisuales y el modo en que sus proyectos se insertaban en los mismos.

Originalmente la investigación surgió como iniciativa de las emisoras y se enmarcó en una convocatoria específica de la Secretaría de Políticas Universitarias orientada a la economía social ${ }^{3}$. Si bien los integrantes de las radios con las que trabajamos tenían una preocupación en torno a cuáles eran sus audiencias, los niveles de conocimiento de las emisoras en sus comunidades, las características a partir de las cuales eran reconocidas, así como las razones para ser o no escuchadas, en general, no contaban con información que les permitiera reconocer sistemáticamente a sus audiencias y rediscutir o reorientar sus proyectos político comunicacionales o sus estrategias de programación. En buena medida, las urgencias en torno a sostener económicamente los proyectos, así como sus respectivas programaciones, fue lo que tendió a concentrar los mayores esfuerzos, aún más en un momento como el referido en el que los embates de las políticas de comunicación generaron una transformación sustantiva de las modalidades de gestión que les dieron origen, inicialmente (Monje y Rivero, 2018; Segura et al, 2018)

En términos metodológicos, los estudios cuantitativos realizados -en cuyos resultados nos concentraremos- se desarrollaron en base a encuestas poblacionales de carácter residencial y probabilístico, basadas en muestras tri-etápicas, aleatorias, con unidades en la primera etapa coincidentes con los límites cartográficos de los radios censales extraídos en primera instancia con probabilidades proporcionales a sus tamaños poblacionales y, en la segunda, y tercera etapa, con probabilidades inversamente proporcionales a dichos tamaños. La muestra final de trabajo para cada ciudad estuvo compuesta por 400 casos. Finalmente, la carga de datos se realizó utilizando Excel y el procesamiento estadístico se realizó con SPSS 22.

Las dimensiones sobre las que se produjo información fueron consumo de medios (televisión, plataformas audiovisuales, diarios, periódicos regionales, internet, consumo digital de medios), y demandas de 
información local. Naturalmente, se hizo énfasis en el consumo de radio, especialmente en las radios locales y en las de tipo comunitaria con las que trabajamos. Pero, además, se incorporaron aspectos específicos de interés para cada radio incorporando indagaciones en torno a algunas preocupaciones específicas sobre determinadas lógicas de consumo: sobre el uso de sus plataformas digitales y redes sociales, sobre el valor y cualidades específicas de las radios reconocidas por la población, entre otras.

Los estudios cualitativos también fueron construidos de manera conjunta. Se trabajó con modalidades diferentes. En dos de las ciudades, se trabajó con entrevistas en profundidad, realizadas en dos encuentros. Fueron en cada caso 15 entrevistas a hombres y mujeres de distintas edades y grupos socioeconómicos de las ciudades de Alta Gracia y Carlos Paz. En las otras dos ciudades se trabajó a través de grupos focales. En la ciudad de Cosquín se realizaron seis grupos focales, en los que el criterio de inclusión para el reclutamiento fue el de trabajar con oyentes de radio entre 31 y 45 años, diferenciados en dos grupos, oyentes de radio Inédita y no oyentes de esta emisora. En Unquillo, se realizaron tres grupos focales, en los que el criterio de reclutamiento fue la pertenencia a organizaciones de esa ciudad (Lunt, 1999; Jensen y Jankowski, 1993; Jacks, 2011).

Las dimensiones abordadas en todos los estudios cualitativos fueron modalidades de escucha, valoraciones y sentidos sobre la radio, en general, y sobre consumo de información. Sin embargo, estas cuestiones se trabajaron siempre en relación con los interrogantes de los integrantes de las emisoras, a través de un proceso por el cual esas inquietudes se fueron elaborando como preguntas en clave comunicacional y se construyeron diversas estrategias de investigación. Con dos de esas radios, se abordó específicamente los distintos tipos de vínculo que establecen con sus audiencias, sobre el modo en que sus oyentes se configuran como públicos, y sobre cuestiones informativas, estéticas y de entretenimiento que les permiten identificarse con ellas. Por otro lado, se trabajó con oyentes de radio sobre aquellas cuestiones por las cuales no eligen las radios con las que trabajamos.

En distintas etapas, dos de las radios plantearon la necesidad de abordar la interacción territorial y comunicacional con las organizaciones locales. Por un lado, porque en el contexto de retroceso y pérdida de derechos que vivimos en el período diciembre 2015- diciembre 2019, que se profundizó en el ámbito comunicacional, estas radios entienden que una cuestión central para su sustentabilidad es el vínculo con las organizaciones sociales de la comunidad, sea tanto para aportar a dichos procesos en términos organizativos, como para potenciarlas a nivel comunicacional, así como también para fortalecer su propio proyecto comunicacional. En este sentido, sus inquietudes estaban relacionadas con los modos en que desde las radios pueden aportar a los procesos organizativos locales, y también a indagar sobre las posibilidades de que esas mismas organizaciones puedan aportar a la sustentabilidad de la radio: aportando contenidos y visibilidad. Para ello, se trabajó en dos relevamientos de organizaciones sociales locales, a través de informantes clave. Luego, se sistematizó dicha información junto con los contactos de los referentes, de modo tal que fuera utilizable como un insumo para la producción informativa. A partir de una muestra construida con las radios, se profundizó con algunas organizaciones cuestiones vinculadas a su situación organizativa y comunicacional para reconocer el modo en que caracterizan sus posibilidades de expresión pública y sus demandas en ese sentido. Y finalmente, se avanzó en una indagación sobre los consumos mediáticos de los integrantes de esas organizaciones, sus posibilidades de expresión pública, y de reconocimiento sobre conflictos locales, sus abordajes comunicacionales, así como de las condiciones y posibilidades para profundizar la interacción comunicativa con las radios.

\section{Pensar las audiencias}

Desde nuestra perspectiva, los estudios de audiencia no pueden ser considerados como una práctica de recuento estadístico de hábitos, sino que es necesario comprender dichas prácticas de consumo, los usos y sentidos que se producen en relación a las propuestas del sistema de medios en el marco de una trama cultural 
y discursiva más amplia de la que forman parte. Asimismo, partir de reconocer las marcas definidas por una experiencia cultural particular: ser público de los medios y reconocerse en sus interpelaciones. La modelación de la cultura mediática, se articula en el marco de una trama más vasta de consumos y prácticas culturales y nos permite examinar las identidades colectivas a partir de ese reconocimiento desde diferentes consumos y prácticas culturales que se articulan con rutinas cotidianas que, a su vez, se encuentran marcadas por las relaciones con esos medios (Mata, 1997, 2002).

En particular, comprender los modos por los cuales se configuran las audiencias en esta trama, hoy supone dar cuenta de la centralidad de las tecnologías de la comunicación y la información para la producción cultural en el capitalismo tardío. Aquello a lo que alude la noción de mediatización, en el que esas tecnologías constituyen el ámbito por excelencia de producción de sentido y articulación cultural, multiplicando y complejizando de manera exponencial la producción discursiva de la sociedad y modificando la ontología tradicional de los hechos sociales (Sodré, 1998); en tanto dispositivos que construyen las nociones de lo real, estas tecnologías aportan decisivamente a configurar nuevas formas de experiencia mediada que reorganizan las relaciones sociales, las identidades individuales y colectivas (Giddens, 2000). Esta matriz se actualiza en diferentes instancias de la vida social en función de articulaciones particulares entre tecnologías y medios con prácticas e instituciones, que son fruto de racionalidades y afectividades específicas y con desigual permeabilidad a la modelación técnica (Mata, 2013; Sodré, 2004; Silverstone, 2004).

Abordar, entonces, la cuestión de las audiencias en sociedades mediatizadas permite reconocer un conjunto de tensiones y preocupaciones que de manera sistemática se actualizan frente a cada nueva tecnología de la comunicación y la información. Lo que Livingstone (2019) ha denominado como nuevo pánico moral, el que se intensifica en el debate social y académico con cada nueva tecnología de la comunicación en clave de determinismo tecnológico. Hoy se problematiza en clave de fake news (falsas noticias que podrían transformar percepciones y voluntades) o Big Data (como esta capacidad inédita de producir información sobre la actividad de los usuarios de internet de modo tal de producir una oferta hipersegmentada que permitiría también moldear sus acciones). Este tipo de preocupaciones, amplificadas por un entorno tecnológico mucho más complejo y empresarialmente concentrado, tienden a tematizarse, veladamente, en una suerte de clave conductista respecto de los comportamientos, gustos y hábitos de las audiencias. Ello es posible, en parte, en tanto las mismas emergen en el debate de manera deshistorizada, naturalizándolas y autonomizándolas de procesos socioculturales más amplios.

Desde este punto de vista, nos distanciamos tanto de las perspectivas empiristas, que consideran que existen audiencias que preexisten y se configuran por fuera de la trama histórica y sociocultural de relación con los medios y las rutinas, tiempos y espacios de la vida cotidiana; así como de aquellas que consideran que se estructuran sólo como un efecto de las tecnologías existentes.

En este contexto, nos interesa destacar que entendemos la dinámica de constitución de las audiencias en su relación comunicativa con los medios que, a su vez, se estructuran en el marco de determinados escenarios mediáticos locales y nacionales históricamente constituidos con específicas y determinadas características. Sin embargo, no sólo deben ser comprendidas desde dicho vínculo. Las audiencias también se construyen en el marco de la vida cotidiana, de la relación de esos individuos con la cultura de la que ellos mismos y los medios forman parte, y de su historia. Sólo en esta trama cultural, materialmente densa y compleja, cobra sentido conocer qué canales o programas son vistos, quiénes escuchan qué radios, qué dispositivos son utilizados para acceder a determinados contenidos, tanto cómo y porqué, las demandas, deseos y el modo en que todo este conglomerado se relaciona con las distintas formas de socialidad, así como los desplazamientos de dichas prácticas.

Dar cuenta del carácter social, histórico y culturalmente denso construido de las audiencias, nos permite avanzar un paso más, para reconocer que se trata de una relación que se configura cotidianamente, cuando los individuos se sienten identificados, hablados por determinadas propuestas de la cultura mediática. 


\section{Las audiencias convergentes: el derrotero de Henry Jenkins}

En este contexto de debates, aparecen algunas nociones que tienden a dar forma y amojonar cierto sentido común académico respecto de las transformaciones recientes en las prácticas de consumo audiovisual en vínculo con el mundo digital. En particular, nos referimos a una noción ampliamente difundida como la de "audiencias convergentes", que opera como deslizamiento de la idea de "consumos convergentes".

Puntualmente es Henry Jenkins quien en Convergence Culture. La cultura de los medios de comunicación(2006), comienza a desarrollar esta discusión respecto de las transformaciones de lo que denomina como cultura convergente, un modo de producción cultural diferente a la previamente existente. Para este autor, la cultura digital estaría centrada en una supuesta deriva de los distintos medios hacia un escenario en el que se combinarían todos los anteriores, lo que denomina como falacia de la caja negra, es decir, la idea por la cual la convergencia es un proceso alrededor de un dispositivo tecnológico particular, como la televisión, en el que se articulan funciones y aparatos diversos en una única tecnología.

Para Jenkins (2006), la cultura convergente "representa un cambio en nuestros modos de pensar sobre nuestras relaciones con los medios, que estamos efectuando ese cambio en primer lugar mediante nuestras relaciones con la cultura popular" (p. 26). De este modo, la convergencia supone el flujo de contenido a través de plataformas mediáticas múltiples, en el que cooperan diferentes industrias mediáticas y "el comportamiento migratorio de las audiencias mediáticas, dispuestas a ir casi a cualquier parte en busca del tipo deseado de experiencias de entretenimiento." (p. 12). Como es evidente, este tipo de circulación de contenidos depende de una participación activa de los consumidores: en este sentido, más que un proceso tecnológico, supone una transformación cultural ligada a las prácticas de los consumidores que logran modificar sus lógicas de consumo, buscan nueva información y establecen conexiones entre contenidos mediáticos dispersos, con una interacción entre productores y consumidores en la que se redefinen sus reglas. Una nueva dinámica en la que ambos participan de manera desigual.

La convergencia, en este sentido, "se produce en el cerebro de los consumidores individuales y mediante sus interacciones sociales con otros. Cada uno de nosotros construye su propia mitología personal a partir de fragmentos de información extraídos del flujo mediático y transformados en recursos mediante los cuales conferimos sentido a nuestra vida cotidiana" (Jenkins, 2006, p. 21). Luego, el eje conceptual estaría depositado en la conversación que se produce, en el consumo como un proceso colectivo capaz de enfrentar el poder mediático, sin desplazar a los viejos medios, sino asumiendo diferentes y complejas formas de interacción entre esos medios tradicionales y los de nuevo tipo.

En este sentido, Jenkins (2006) va a sostener que "la convergencia mediática es más que un mero cambio tecnológico. La convergencia altera la relación entre las tecnologías existentes, las industrias, los mercados, los géneros y el público. La convergencia altera la lógica con la que operan las industrias mediáticas y con la que procesan la información y el entretenimiento los consumidores de los medios. Tengan bien presente que la convergencia se refiere a un proceso, no a un punto final" (p. 28) en el que el entorno tecnológico genera expectativas de un flujo más libre de contenidos e ideas, en las que los consumidores tienen mayores posibilidades de disputar su participación en la cultura.

En esta línea, Guillermo Orozco Gómez retoma esta perspectiva, articulada con los aportes de Manuel Castells (2009) y su concepto de "autocomunicación masiva": una combinación entre la reacción a los medios masivos, la interacción con sus productos, la actividad con ellos en otros canales de interlocución y la eventual producción de comunicación propia difundida a muchos otros. Fundamentalmente, esta mirada supone otros modos de ser audiencia vinculada a una mayor capacidad de interlocución en el diálogo social. En este sentido, para Orozco Gómez (2013), esta transformación habilitaría abordar "las acciones, reacciones e intercambios pasivos o activos, críticos o ingenuos, oportunos o a destiempo, directos o diferidos que diferentes audiencias tienen con productos audiovisuales específicos" (p.10). Así, reconoce en la interacción / recepción transmediática un creciente fenómeno ligado tanto con las respuestas de las audiencias a un 
producto mediático, como a las conversaciones múltiples entre pares en redes sociales. En este marco, el autor plantea una condición comunicacional en la cual, la mediación técnica como mediación cultural, habilita una transformación sustantiva de las audiencias en las sociedades actuales, en función de la cual dejarían de ser reconocidas por su estatus esencialmente ligado a procesos de recepción y a una actividad manifiesta escasa como interlocutores con el poder, para pasar a estar caracterizadas por "estar y ser activos, cada vez más creativos, en la producción y emisión comunicacional” (Orozco Gómez, 2010, p. 6).

Entonces, lo que parece estar condicionando la conceptualización sobre las transformaciones de las prácticas de consumo audiovisual en los procesos de convergencia, sería la posibilidad de abordar lo que aparece como una participación manifiesta en la conversación social, en diferentes modalidades y escalas, pero siempre mediadas e impulsadas tecnológicamente. En este sentido, la idea de unas audiencias "pasivas" ligadas a los grandes medios de comunicación de masas, funciona como contrapunto para dar cuenta de la novedad que habilita el nuevo entorno tecno comunicacional. Sin embargo, desde nuestra perspectiva, dicha pasividad no es tanto una condición de las audiencias como una dificultad analítica de estos enfoques para reconocer tanto los vínculos en los que se articula la relación medios / audiencias, como las modalidades de participación en el diálogo social vinculada a la interacción con los medios de comunicación en la que la dinámica de esa participación no se expresa de manera manifiesta, ni necesariamente mediada por las tecnologías de la comunicación y la información.

Para nosotros, abordar los procesos de conformación de audiencias en contextos de convergencia tecnológica, supone insertar la discusión en una trama más extensa de debates de los estudios de comunicación. Para comprender los modos en que se configuran las audiencias, entendemos que es necesario considerar algunos supuestos: entendemos que la audiencia no es un conjunto empírico de individuos, sino que se trata de una noción que nos permite conocer colectivos con ciertas variables comunes de gustos, preferencias, necesidades y usos que les brinda una cierta identidad común. A su vez, la indagación de las audiencias tampoco puede ser reducida a la comprensión de los procesos de recepción, en tanto se trata de un abordaje centrado en reconocer la producción de sentido en relación a determinados productos mediáticos.

\section{Los consumos audiovisuales del Gran Córdoba}

En función de estas discusiones, nos interesa retomar algunos de los datos producidos en los estudios sobre consumos y audiencias que hemos realizado ${ }^{4}$. Si bien los mismos no son generalizables más que a las poblaciones en las que fueron producidos, ciudades cuyas características ya señalamos, entendemos que aportan a comprender y discutir ciertas dinámicas de estructuración de las audiencias actuales.

De cualquier manera, toda vez que resulte relevante, incorporaremos como parte del análisis los datos producidos por el Sistema Nacional de Consumos Culturales del año 2017, ya que es la referencia pública de alcance nacional, más relevante en la materia. Este tipo de contrastación nos permitirá contemplar ciertos parámetros y señalar divergencias y convergencias con estos datos. 


\section{Consumo de TV}

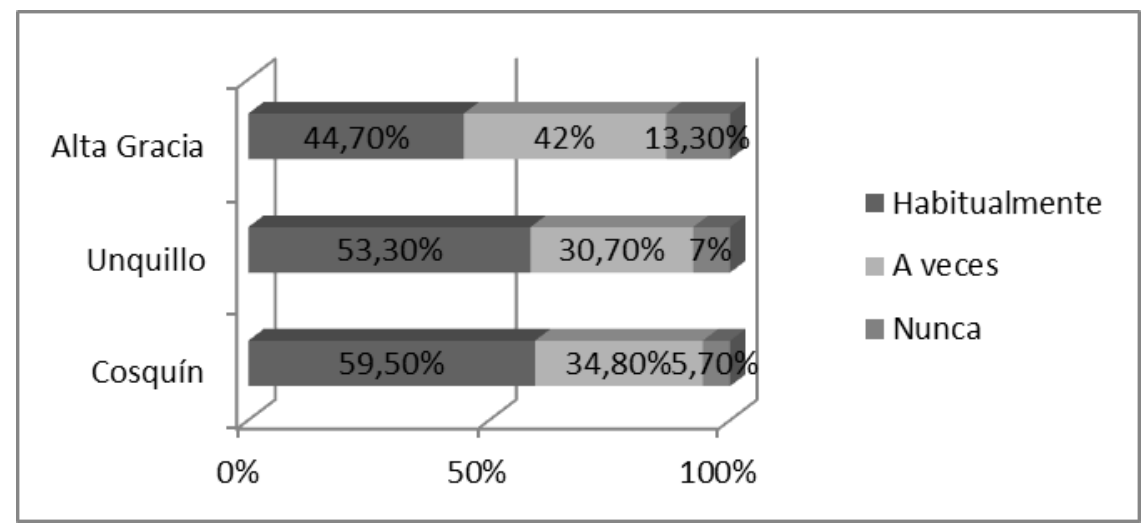

GRÁFICO 1

Consumo de TV.

Fuente: Producción propia

En nuestra investigación la TV es consumida regularmente por un 93\% de la población en Unquillo, un 94\% en Cosquín y un 87\% en Alta Gracia. Es decir que, prácticamente, sólo 1 de cada 10 ciudadanos de estas localidades del Gran Córdoba no suele ver TV de manera regular. El altísimo nivel de consumo de este medio, próximo a cumplir 70 años en nuestro país, ha sido también verificado por el último y reciente estudio del SINCA (2017, p.15).

De modo particular, vale señalar que contrario a lo que se suele suponer sobre que los jóvenes están dejando de consumir la TV, no es claro que en estas tres localidades se verifique este fenómeno de manera homogénea.

En ese sentido, en Unquillo el consumo de TV entre los jóvenes no tiende a la baja. Todo lo contrario: son quienes dicen verla con mayor habitualidad. De manera distinta, aquellos que no ven televisión se concentran, fundamentalmente, entre los entrevistados de 31 a 45 años. Esta situación probablemente se encuentre vinculada con los horarios y tiempos laborales de esta franja de entrevistados ${ }^{5}$. En Alta Gracia, a su tiempo, los entrevistados entre 21-30 años son quienes más consumen TV. Por su parte, en la ciudad de Cosquín sí puede observarse un menor nivel de consumo de la TV por parte de los jóvenes, en relación al resto de la población local.

Como podrá notarse, los desplazamientos y lógicas actuales de la constitución de audiencias de la TV, no pueden entenderse como un proceso homogéneo y uniforme. De manera distinta, asistimos a fenómenos no necesariamente vinculados con el medio en sí, sino, probablemente, con las ofertas y lógicas de programación de la Televisión que tienden a no resultar de interés para los jóvenes de algunas localidades.

En términos socioeconómicos sí caben lecturas algo más generales ya que quienes más consumen TV son los sectores con menores ingresos, así como aquellos que tienen niveles educativos más bajos.

En cuanto al sistema de TV, al menos el $50 \%$ de los encuestados mira televisión por sistema de cable, mientras que los que miran por aire rondan entre el $17 \%$ y el $20 \%$ de los encuestados. Este porcentaje es sensiblemente menor a la media nacional, situada en el 73\% (SINCA, 2017).

A su tiempo, el uso de plataformas on demand alcanza el 37\% de los encuestados. Si bien esta modalidad de consumo de contenidos audiovisuales crece a medida que se elevan los niveles de ingresos y el nivel educativo, estamos lejos de hablar de una sociedad plena y homogéneamente digitalizada.

En cuanto a las ofertas, los canales más consumidos son los provinciales de TV abierta (a los que se accede por cable o por aire, mientras que están ausentes de los sistemas de TV Satelital), y en ellos, los programas de tipo informativos. De modo específico, en todos los grupos sociales predomina el consumo de Canal 12 (local de aire, propiedad del Grupo Clarín) cuyos niveles de audiencia crecen entre los encuestados de menor nivel socioeconómico y educativo. 
En este punto resulta destacable que al indagar qué miran los televidentes, un número importante asocia su consumo con determinados canales: esto es, los medios específicos continúan articulando tradiciones de consumo, mucho más que los programas particulares o las figuras periodísticas, sean del entretenimiento o artísticas.

Finalmente, en cuanto a los dispositivos, de manera concomitante con los resultados del SINCA, el televisor es el principal dispositivo para mirar TV: ni el celular, ni la tablet ni la computadora superan el $15,1 \%$ en ninguna de las localidades analizadas.

\section{Consumo de RADIO}

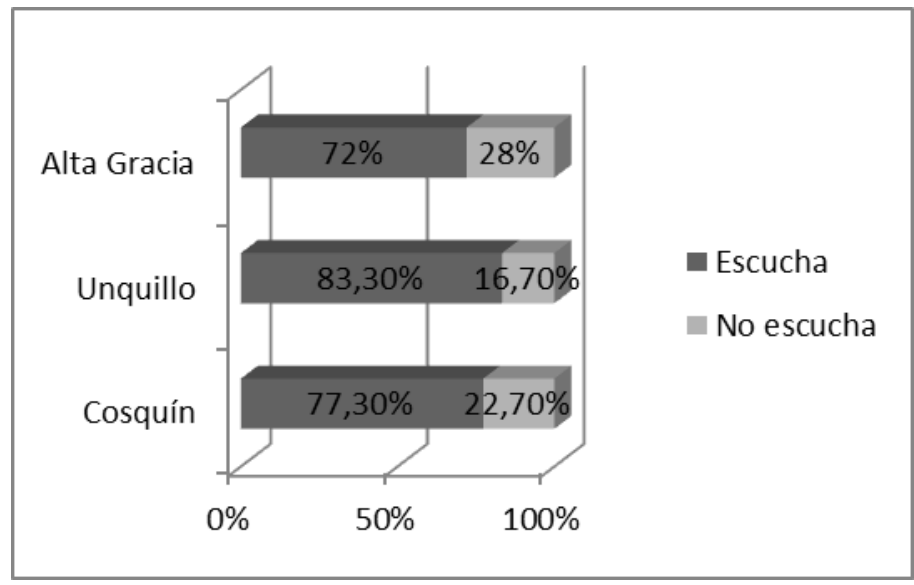

GRÁFICO 2

Escucha de radio

Fuente: producción propia

Si bien menos consumida que la TV, la radio es escuchada regularmente por un altísimo porcentaje de población de las localidades analizadas: el 84\% en Unquillo, el 77\% en Cosquín y 72\% en Alta Gracia. En este punto vale señalar, que estos niveles se encuentran marcadamente por encima del promedio nacional de escucha, reconstruido por el último estudio del SINCA, en 70\% (2017, p. 12). Aquí cabría considerar que venimos señalando la vitalidad del medio y el alto nivel de pervivencia del mismo como un aspecto característico de la radio y las audiencias locales cordobesas (Martínez Luque, 2013).

Distinto a la TV, en el caso de la radio sí puede reconstruirse más claramente una relación entre la edad y niveles de consumo: en las tres localidades este medio es más escuchado entre los adultos de 31 a 45 años, pero desciende en los que tienen más edad. Este dato, en relación con la edad, es relevante en tanto funciona de manera inversa al consumo de televisión; además es destacable que, más que una audiencia avejentada, la radio aparece como un medio de edades medias. Mientras tanto los menores de 25 años son los que tienden a consumir menos radio. Sin embargo, no es cierto que los jóvenes no escuchan radio; lo hacen en menor proporción.

Las audiencias de radio aparecen de manera fuertemente fragmentadas. En cada uno de los estudios, si bien el consumo se articula alrededor de tres radios principales, se nombran más de 40 emisoras en cada uno de ellos, vinculado a una realidad de propuestas hipersegmentadas desde la oferta. De esta manera, en general, se escuchan dos o tres radios diferentes, combinando ofertas de AM y FM al tiempo que resulta muy bajo el porcentaje de oyentes que escucha una sola emisora: en ninguno de los estudios supera al $15 \%$.

En cuanto a los dispositivos, la escucha se realiza principalmente a través de aquellos de carácter analógico; por el contrario, sólo un $21 \%$ utiliza alguna vez el acceso digital y sólo un $5 \%$ utiliza sólo modalidades digitales de escucha. 
Un dato relevante para el tipo de estudio que realizamos es la centralidad de la escucha de los medios locales; en la provincia de Córdoba, el consumo de radio se concentra en 3 radios: Cadena 3 (con porcentajes en torno al 24\%), 100.5 (con porcentajes en torno al 16\%) y Popular (con porcentajes en torno al 13\%), las tres propiedades del Grupo local Radiodifusora del Centro S.A. En los estudios realizados, a partir del tercer o cuarto lugar, según la localidad, se posicionan las radios locales de cada ciudad, entre ellas las emisoras cooperativas que analizamos, con porcentajes que van del 9\% al 23\% de oyentes.

\section{EL USO DE INTERNET}

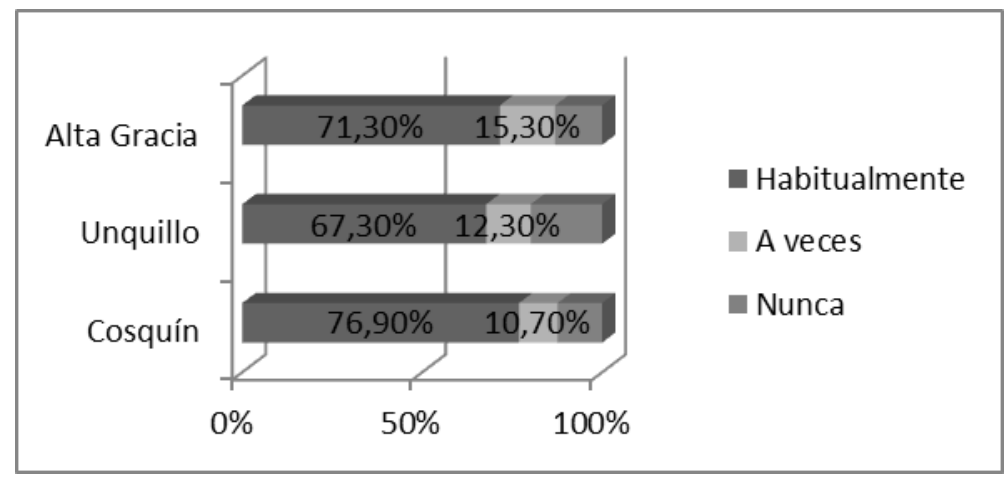

GRÁFICO 3

Uso de internet.

Fuente: Producción propia

Hemos dicho que tanto la TV como la radio tienen un altísimo nivel de consumo general. En gran medida, especialmente en el plano radiofónico, el mismo se encuentra vinculado con propuestas que dan cuenta de las realidades locales y cercanas. No obstante, ello, no quita -de hecho, todo lo contrario- que internet sea también muy importante en términos de consumo masivo. Así, en Cosquín el 87\% utiliza Internet regularmente; en Unquillo el 79\% accede con la misma frecuencia; mientras que en Alta Gracia lo hace el $72 \%$.

En las tres localidades se verifican distinciones en el uso de internet vinculadas con el sector social y con la edad. En cuanto a lo etario, observamos que mientras más jóvenes son los encuestados mayor es el uso y la frecuencia del mismo. A su tiempo, este consumo regular crece marcadamente a medida que se incrementan los niveles de ingreso, alcanzando en los sectores altos de Cosquín al 100\% de los entrevistados. De todas maneras, en este punto, quisiéramos señalar un dato especialmente llamativo. Seguramente de la mano de la ampliación del uso de los teléfonos celulares inteligentes y de la extensión del servicio de internet a través de dichos dispositivos, en estas localidades, en todos los segmentos sociales el uso regular de internet alcanza al menos al 70\% de los entrevistados. Es decir, que internet, aún con todas las lógicas de usos dispares que puede acunar, resulta hoy un consumo ampliamente extendido. Este tipo de tendencia ha sido también verificada en relación a las mismas variables en el Sistema Nacional de Consumos Culturales (2017, p. 32).

El uso principal de internet se concentra en consultar redes sociales. El 60\% dice utilizarla con dicho fin; esto se observa de manera más acentuada en los más jóvenes mientras que a medida que se incrementa la edad se diversifica el uso de internet, siendo la consulta de diarios, portales informativos y la búsqueda de información los aspectos más mencionados. A su tiempo, entre los sectores bajos y muy bajos de estas localidades el uso principal de internet también está orientado a acceder a redes sociales.

Es destacable que los principales sitios mencionados como fuentes informativas se corresponden con medios que concentran importantes niveles de audiencia en otros soportes tales como canales de televisión (TN), radios (Cadena 3) y diarios (Clarín, Infobae, La Voz del Interior) que, al mismo tiempo, desarrollan una propuesta de tipo digital. 
Finalmente vale mencionar que el $35 \%$ de los encuestados utiliza internet para distintos tipos de consumo audiovisual (series, películas, videos, música, radio o TV).

\section{Algunas Discusiones DeSDe los Resultados}

Estos resultados nos permiten plantear algunas cuestiones en torno a la caracterización de los consumos audiovisuales actuales.

En primer lugar, podemos observar que no se verifican medios sectorialmente y homogéneamente abandonados. En ese sentido, son falaces las imágenes que plantean que los jóvenes no escuchan radio o han abandonado la TV o aquellas otras que, acudiendo a estereotipos diversos o generalizaciones poco serias, esgrimen que los sectores más vulnerables se encuentran fuera del mundo digital.

De todas maneras, si bien no de manera totalizante, es posible reconocer algunas tendencias relativamente nítidas que es preciso señalar: los nuevos medios digitales logran mayor inserción entre jóvenes y franjas con mayores ingresos, mientras que la radio y TV mantienen mejores niveles de consumo entre los de mayor edad y las clases medias, medias bajas y bajas.

En cualquier caso, ante un panorama en el que lo analógico y lo digital -tanto en dispositivos como lógicas de programación y ofertas comunicativas de contenidos- compiten por la atención, se entremezclan, solapan y potencian cabe avanzar en concebir los consumos audiovisuales como múltiples, coexistentes y desiguales.

En este sentido, no podemos acordar con la idea de un proceso homogéneo de desplazamiento de los medios audiovisuales tradicionales por parte de los emergentes de tipo digital. Aún atravesados por la concentración empresarial de medios, nuestro país acuna una importante cantidad de escenarios mediáticos regionales y locales estructurados históricamente de modos diversos. Dicha historia de diversidad y diferencia también habla de consumos y audiencias que deben ser reconocidos en sus particularidades para no realizar generalizaciones engañosas producidas desde las urbes metropolitanas.

En este sentido, observamos que, frente a una estructura mediática nacional y global extremadamente concentrada -cuyas agendas tienden a encontrarse reñidas con la pluralidad informativa de temáticas, actores y ámbitos geográficos ${ }^{6}-$, los medios locales, aún tradicionales, se consolidan como lugares de reconocimiento que el consumo nombra.

Por otra parte, advertimos consumos de medios coexistentes: son a la vez, ambientales, grupales e individuales. Dicha coexistencia no repara en tipos de soportes sino en contenidos, tiempos y rutinas destinados al consumo audiovisual. Sin embargo, esta simultaneidad no puede ser confundida con equiparación, democratización o avances en pluralidad comunicativa. De modo distinto, observamos que el ordenamiento de los consumos se encuentra fuertemente modelado, desde lo analógico y lo digital, por la estructura privada de producción fuertemente concentrada en muy pocos grupos empresariales de medios.

Asimismo, los consumos y audiencias que hemos avanzado en caracterizar también están configurados por la desigualdad. En un plano, la misma puede ser leída en la mayor pregnancia de la TV y la radio, los únicos medios que siguen siendo gratuitos para las audiencias, entre los sectores medios bajos y bajos. Si bien allí también vemos las marcas de procesos culturales de más largo aliento, los distintos modos y velocidades de apropiación de lo digital están, en un mismo tiempo, fundados en condiciones materiales: el servicio pago de datos e internet aún opera como barrera de uso para los sectores de menores recursos. En otro plano, la desigualdad en los consumos también se observa en la variedad de apropiaciones y de usos de lo digital; son los sectores de más bajos ingresos quienes menor gama de usos le asignan a internet, siendo casi exclusivo la utilización de redes sociales. 


\section{UN CAMPO MINADO DE PREGUNTAS}

Estos reconocimientos nos permiten plantear algunos interrogantes que complejizan los términos del debate sobre las transformaciones de las prácticas de consumo audiovisual y de estructuración de las audiencias. Los mismos son una invitación a profundizar un debate y a avanzar en investigaciones que nos permitan comprender procesos específicos de conformación de audiencias sin perder de vista cuestiones estructurales articuladas de manera diferencial en las prácticas de consumo.

\section{1. ¿Quiénes producen información sobre el proceso de convergencia?}

En la actualidad existe una posibilidad amplia e inédita de producir información sobre las prácticas de consumo ligadas a lo digital. Sin embargo, los enormes caudales de datos producidos por los propios dispositivos digitales solo están al alcance de los actores privados que dominan la escena, particularmente de las grandes empresas ligadas al tema que proveen los servidores de búsqueda. En este marco, solemos asistir a la publicación orientada de dicha información, generalmente parcial y carente de rigurosidad metodológica aparente, con el objetivo de configurar los términos del debate en torno a la convergencia digital.

A su turno, los diferentes niveles de Estado, aunque con avances en algunas áreas vinculadas a la gestión, así como los espacios académicos universitarios, han demostrado enormes dificultades para producir conocimiento empírico, público, riguroso y actualizado que favorezcan un debate crítico sobre la cuestión. Como se sabe, los procesos de investigación son costosos, tanto en términos de los estrictos recursos económicos necesarios como de los posicionamientos públicos que los mismos conllevan.

En cualquier caso, recuperar la iniciativa desde el sector público en la producción de información sobre los consumos audiovisuales y, en particular, sobre los de tipo digital nos permitirá construir lecturas que den cuenta del proceso de manera integral, con sus contradicciones, complejidades y desigualdades. Y, a su vez, nos permitiría avanzar en la discusión, de manera fundada, sobre las políticas públicas urgentes para resguardar los derechos de las audiencias en el marco de la etapa actual de las comunicaciones.

2. ¿Lo digital libera?

En el marco de una mixtura poco original -entre el deseo libertario del progresismo global y la ventana de oportunidades para la generación de nuevos negocios para los sectores concentrados-, se ha promovido y acunado la idea de que los nuevos medios digitales, y ahora la convergencia, permiten resolver las carencias de la democracia comunicativa, tanto desde su faz de libre expresión como en la correspondiente al acceso a la libre información.

Con convergencia Jenkins -y su estela teórica- pretende nombrar, a un tiempo, el proceso de convergencia mediática, la cultura participativa, así como la inteligencia colectiva. En este sentido, para Jenkins, y en buena medida también para Guillermo Orozco, en la cultura de la convergencia "el poder del productor y el consumidor mediático interaccionan de maneras impredecibles" (Jenkins, 2006, p. 14). Puntualmente, al respecto, se ha planteado que el entorno tecnológico genera expectativas de un flujo más libre de contenidos e ideas, en las que los consumidores tienen mayores posibilidades de disputar su participación en la cultura.

Fruto de ese deseo y expectativa se ha instalado y naturalizado de manera preocupante el mito del prosumidor: aquella figura que difumina las distancias y jerarquías entre los polos de producción audiovisual y su recepción; aquella figura que agita, quizás como nunca antes, la libre actividad potencial y creativa de las audiencias. 
El problema reside en que, salvo en estos discursos circulantes promovidos desde los actores del mercado en función de tal ideario, no tenemos datos que avalen tales grados de libertad, en forma generalizada.

Hasta ahora, a todas luces, no se puede observar mayor democracia comunicacional sino nuevos terrenos de su cercenamiento y nuevas instancias en las cuales el Estado debe hacerse presente para asegurar el respeto a los derechos de las audiencias.

3. ¿Qué hay de viejo en lo nuevo?

De modo permanente, observamos cómo se construye la imagen del desplazamiento de los nuevos medios y tecnologías de información respecto de medios tradicionales; como hemos intentado dejar en claro no disponemos de datos homogéneos y definitivos que puedan avalar dichas lecturas. Por el contrario, es necesario dar cuenta de la centralidad de los contenidos audiovisuales tradicionales y las modalidades en que los mismos se reproducen mediante su circulación digital.

4. ¿Existen las audiencias convergentes?

Los trabajos de comunicación circulantes tienden a pensar las denominadas prácticas de "consumos convergentes" de las audiencias como una suerte de efecto o resultado de la existencia de los procesos de convergencia tecnológica y de producción audiovisual. Suponen así, que, por la existencia de unos, pueden inferirse similares características de las audiencias.

Es claro que la producción audiovisual a gran escala está organizada con la lógica de la convergencia, sin embargo, pensar las transformaciones en las prácticas de consumo audiovisual exclusivamente desde dicha noción, supone replicar la lógica de la producción de contenidos en la esfera de los consumos, sin mediaciones, desplazamientos ni tensiones de ningún tipo. Quizás esta tendencia pueda atribuirse a la estela teórica de lo planteado originalmente por Henry Jenkins, pero fundamentalmente debería leerse como consecuencia de la escasa investigación empírica situada sobre las audiencias que se desarrolla en nuestro país.

Lejos de una inferencia tecnologicista o de generalizaciones insostenibles a partir de datos de algunas metrópolis centrales, componer la realidad actual de las audiencias de nuestro país demanda producir conocimiento crítico y situado en diferentes ámbitos y escenarios locales. Solo reponiendo las complejidades, tensiones y desplazamientos de los consumos audiovisuales podremos acercarnos a discutir con seriedad los impactos de los procesos de convergencia en los consumos y los procesos de constitución de las audiencias.

En este contexto, por ahora, y con el nivel de precisiones conceptuales con que el campo de estudios de la comunicación define la cuestión, es claro que resulta falaz, engañoso y poco productivo hablar de audiencias o consumos convergentes.

En otro plano, resulta relevante escapar de la discusión tecnologicista introduciendo la dimensión cultural del debate; desde una perspectiva materialista de la cultura creemos necesario avanzar en preguntarnos cuáles son las características del proceso cultural que habilitan la posibilidad de las coexistencias, multiplicidades, y tensiones en los consumos audiovisuales, en el marco de transformaciones económicas, sociales e incluso urbanas más amplias. Cabe aquí preguntarse: ¿cómo operan entre los nuevos y viejos consumos las lógicas preexistentes de individualización, fragmentación social y privatización de la vida común?; ¿cómo se construye lo común, lo compartido, lo afectivo en consumos coexistentes, múltiples y desiguales? ¿qué lugar tiene el componente tradicional y rutinario de los consumos en los deslizamientos y coexistencias que observamos?

La representación que es promovida y replicada de la convergencia comunicacional suele ofrecer una imagen del proceso de tipo vórtice: las distintas pantallas, soportes y tecnologías giran centralizadamente en torno a lo novedoso, absorbidas -inexorablemente- por lo digital. Por ello muchas veces se nos conduce a pensarlo como un proceso homogéneo, uniforme y lineal. De modo 
contrario, como hemos intentado dejar sentado, las prácticas muestran variedad, heterogeneidad, vinculaciones con lo local y anclajes en tradiciones de consumo de larga data que tensionan la idea usualmente circulante de la convergencia desde las audiencias. El proceso que vivimos resulta mucho más complejo de lo que algunos sectores están dispuestos a aceptar.

En ese sentido, desde los espacios de producción de conocimiento en los que participamos nos interesa, aún con las limitaciones y dificultades presupuestarias que encontramos en nuestras universidades públicas, reconstruir y ofrecer otras imágenes conceptuales de la realidad de las audiencias; una manera de pensarlas que, en definitiva, permita aprehender las complejidades, heterogeneidades y desigualdades en función de las cuales las mismas se han configurado.

\section{REFERENCIAS}

Castells, M. (2009). Comunicación y poder. España: Alianza.

Giddens, A. (2000). Modernidad e identidad del yo. Barcelona: Península.

Jacks, N (2011). Análisis de recepción en América Latina: un recuento con perspectiva a futuro. Quito: CIESPAL.

Jenkins, H. (2006). Convergence culture. La cultura de la convergencia de los medios de comunicación. Barcelona, Buenos Aires y México: Paidós.

Jensen, K. B. y Jankowski, N. W. (eds.) (1993). Metodologias cualitativas de investigación en comunicación de masas. Barcelona: Bosch

Kejval, L (2017). Investigar desde la comunicación alternativa, popular y comunitaria. AVATARES de la comunicación y la cultura, (13), pp. 31-47

Livingstone, S. (2019). Audiences in an Age of Datafication: Critical Questions for Media Research. Television \& New Media, 20(2) pp. 170- 183.

Lunt, P. (1999). Comentarios sobre Chilton y Hutchinson: más allá de los problemas de medición en el método del grupo focal. Journal of Communication, Oxford academic. pp. 79 - 98.

Magallanes, C; Ramos, D.; Castells, S. y Parra, D. (2010). Un enfoque participativo de investigación para la comunicación comunitaria en México. Revista Folios, (24), pp. 141 -162.

Martínez Luque, S. (2013). Trayectorias radiofónicas: aportes para una historia de la radio de Córdoba (Argentina) 1988-2002. Revista Brasileira da História da Mídia, 3 (1), pp. 53-63.

Mata, M. C. (1997). Medio masivos: Lo que nombra el consumo. Revista Estudios. pp. 215-222.

Mata, M. (2002). Comunicación, ciudadanía y poder. Diálogos de la Comunicación, (64), pp. 64-75.

Mata, M.; Morales, S; Martinez Luque, S.(2016). Monitoreo de los noticieros de la televisión de aire de la ciudad de Córdoba. Informe Anual 2014. Córdoba, Argentina: Editorial Centro de Estudios Avanzados. Colección Documentos de Trabajo.

Monje, D. y Rivero, D. (2018). Televisión Cooperativa y Comunitaria. Diagnóstico, análisis y estrategias para el sector no lucrativo en el contexto convergente. Córdoba: Convergencia cooperativa.

Orozco Gómez G. (2010). Audiencia ¿siempre audiencias? Hacia una cultura participativa en las sociedades de la comunicación. Texto de la Conferencia Inaugural del XXII Encuentro Nacional AMIC. Universidad Iberoamericana, México DF. Recuperado de https://es.scribd.com/doc/162579688/AUDIENCIAS-siempreAudiencias-Guillermo-Orozco-pdf

Orozco Gómez, G. (2013). ¡Que vivan las audiencias!. Comunicación y sociedad (20), 233-237. Recuperado http://w ww.scielo.org.mx/scielo.php?script=sci_arttext\&pid=S0188-252X2013000200011\&lng=es\&tlng=es

Segura, S; Longo, V; Traversaro, N; Linares, A; Vinelli, N y Espada, A. (2018). Los públicos de medios comunitarios, populares y alternativos en América Latina. El caso argentino. COMMONS. Revista de Comunicación y Ciudadania Digital, pp. 15-45.

Silverstone, R. (2004). ¿Por qué estudiar los medios? Buenos Aires, Argentina: Amorrortu. 
Sistema Nacional de Consumos Culturales. SINCA (2017). Encuesta Nacional de Consumos Culturales. Informe General. Recuperado de https://www.sinca.gob.ar/VerDocumento.aspx?IdCategoria=10

Sodré, M. (1998). Reinventando la cultura, la comunicación y susproductos. Barcelona, España: Gedisa.

\section{Notas}

1 Estas ciudades se encuentran en un radio de $60 \mathrm{~km}$ de la ciudad de Córdoba. Son ciudades que en los últimos quince años han sufrido enormes cambios demográficos, en los que ha crecido de manera exponencial su población, transformando su perfil turístico en ciudades metropolitanas que funcionan en buena medida como ciudades dormitorio para habitantes que desarrollan sus actividades en la ciudad capital.

2 Este artículo es producto del proyecto Radios cooperativas y públicos. Estudios de consumos y audiencias en el Gran Córdoba. Parte I y II. El proyecto, dirigido por la Dra. María Liliana Córdoba, contó con el asesoramiento de la Prof. María Cristina Mata, y fue llevado adelante por integrantes del Programa de Estudios sobre Comunicación y Ciudadanía del Centro de Estudios Avanzados de la Facultad de Cs. Sociales de la Universidad Nacional de Córdoba, del que formo parte.

3 Programa de Cooperativismo y Economía Social en la Universidad. Secretaría de Políticas Universitarios del Ministerio de Educación de la Nación.

4 Vamos a considerar sólo los datos de tres de los estudios cuantitativos, ya que el realizado en la ciudad de Carlos Paz estuvo orientado, específicamente, a personas con participación en organizaciones político territoriales no a población, en general.

5 Los informes públicos del proyecto de investigación, donde aparece toda la información complementaria que en este artículo no podemos presentar, están publicados en: http://universidadyeconomiasocial.siu.edu.ar/inicio

6 Hemos revisado la cuestión informativa en Mata, Morales y Martinez Luque (2016). 